\title{
Where Is the Spike Generator of the Cochlear Nerve? Voltage-Gated Sodium Channels in the Mouse Cochlea
}

\author{
Waheeda A. Hossain, Srdjan D. Antic, Yang Yang, Matthew N. Rasband, and D. Kent Morest \\ Department of Neuroscience, University of Connecticut Health Center, Farmington, Connecticut 06030
}

The origin of the action potential in the cochlea has been a long-standing puzzle. Because voltage-dependent $\mathrm{Na}^{+}(\mathrm{Nav})$ channels are essential for action potential generation, we investigated the detailed distribution of Nav1.6 and Nav1.2 in the cochlear ganglion, cochlear nerve, and organ of Corti, including the type I and type II ganglion cells. In most type I ganglion cells, Nav1.6 was present at the first nodes flanking the myelinated bipolar cell body and at subsequent nodes of Ranvier. In the other ganglion cells, including type II, Nav1.6 clustered in the initial segments of both of the axons that flank the unmyelinated bipolar ganglion cell bodies. In the organ of Corti, Nav1.6 was localized in the short segments of the afferent axons and their sensory endings beneath each inner hair cell. Surprisingly, the outer spiral fibers and their sensory endings were well labeled beneath the outer hair cells over their entire trajectory. In contrast, Nav1.2 in the organ of Corti was localized to the unmyelinated efferent axons and their endings on the inner and outer hair cells. We present a computational model illustrating the potential role of the Nav channel distribution described here. In the deaf mutant quivering mouse, the localization of Nav1.6 was disrupted in the sensory epithelium and ganglion. Together, these results suggest that distinct Nav channels generate and regenerate action potentials at multiple sites along the cochlear ganglion cells and nerve fibers, including the afferent endings, ganglionic initial segments, and nodes of Ranvier.

Key words: axon initial segment; Nav1.6; Nav1.2; spiral ganglion; cochlear nucleus; hair cells; quivering mutation; computational model

\section{Introduction}

Hearing commences when hair cells in the organ of Corti of the inner ear transduce sound energy into electrical signals that cross the recepto-neural junctions to depolarize sensory axons in the cochlear nerve. Action potentials (APs) propagate along axons of bipolar cochlear ganglion cells, forming point-to-point connections between hair cells and the cochlear nucleus (see Fig. 1A,B). There are two types of ganglion cells. Type I is myelinated, innervates one inner hair cell each, and provides rapid discrete coding. Type II is unmyelinated, and each innervates up to 30-60 outer hair cells (Spoendlin, 1973; Perkins and Morest, 1975; Kiang et al., 1982; Ginzberg and Morest, 1983; Liberman et al., 1990). Efferent fibers, arising in the superior olivary nuclei, innervate either inner or outer hair cells and their sensory endings and may have feedback functions (Brown, 1987). However, the function of type II ganglion cells is not very well understood.

The complex innervation of the sensory epithelium by unmyelinated axons and differences between ganglion cell types raise important questions about the sites of AP initiation and regeneration. Moreover, interpolation of the ganglion cell body in the course of each afferent axon poses an obstacle to the rapid prop-

Received Jan. 11, 2005; revised June 8, 2005; accepted June 9, 2005

This work was supported by National Institutes of Health Grants NS29613 (D.K.M.), DC06387 (D.K.M., W.A.H.), MH063503 (S.D.A.), and NS044916 (M.N.R.). We thank Jeffrey Dutton for help with imaging and the conversions for the computational analysis and Allic Sivaramakrishnan for technical help with the simulations.

Correspondence should be addressed to Dr. Waheeda A. Hossain, Department of Neuroscience, University of Connecticut Health Center, 263 Farmington Avenue, Farmington, CT 06030-3401. E-mail: whossain@neuron.uchc.edu.

DOI:10.1523/JNEUROSCI.0123-05.2005

Copyright $\odot 2005$ Society for Neuroscience $\quad$ 0270-6474/05/256857-12\$15.00/0 agation of APs necessary for accurate acoustic processing (Santos-Sacchi, 1993).

In neurons, APs are generated by a variety of voltagedependent $\mathrm{Na}^{+}$(Nav) channels. In central neurons, the predominant $\alpha$-subunits are Nav1.1, Nav1.2, Nav1.3, and Nav1.6 (Gong et al., 1999; Alessandri-Haber et al., 2002; Schaller and Caldwell, 2003). These channels are both temporally and spatially regulated. For example, Nav1.1 is expressed mainly on neuronal somata, Nav1.2 on unmyelinated axons, and Nav1.6 at axon initial segments and nodes of Ranvier (Gong et al., 1999; Caldwell et al., 2000; Boiko et al., 2001). In the peripheral nervous system, additional Nav channels may include Nav1.7, Nav1.8, and Nav1.9 (Sangameswaran et al., 1997; Toledo-Aral et al., 1997; Dib-Hajj et al., 2002). These, along with some of the same channels found in the CNS (e.g., Nav1.6), may be expressed in functionally distinct neurons with unique patterns of localization. The molecular mechanisms regulating differential expression, targeting, and localization of Nav channels are just beginning to be uncovered (Garrido et al., 2003; Lemaillet et al., 2003).

To understand better the mechanism of AP generation and propagation in the cochlea, we investigated the differential distribution of Nav channels. We show that Nav1.6 and Nav1.2 occur in distinct subcellular domains of cochlear neurons, in which they may function as spike generators. We show that quivering $\left(q v^{3 J}\right)$ mutant mice have defective clustering of Nav1.6 channels in the cochlea, consistent with the deaf phenotype. Finally, a computational model for the type II ganglion cell confirms that three distinct axonal regions with high Nav channel densities are all critical for AP initiation and propagation. Our findings show 
that multiple spike generators at precise locations on the cochlear ganglion axons are required for hearing.

\section{Materials and Methods}

Animals. Data were obtained on 14 F1 hybrids from timed matings of male CBA/J and female C57BL/6J mice (The Jackson Laboratory, Bar Harbor, ME). Four C57BL/6J-Spnb $4^{q v-3 J} / \mathrm{J}$ (quivering) mice were from a mutant mouse line (The Jackson Laboratory), which was maintained by heterozygote intercrosses. Identification of homozygous mutants was performed as described previously (Yang et al., 2004). In this breeding colony, homozygotes did not respond to a broadband white noise delivered at nondamaging levels in a sound-proof chamber with either a visible startle response or a Preyer reflex, both of which were readily apparent in the wild type. All procedures were approved by the Institutional Animal Care Committee at The University of Connecticut Health Center and conform to the United States Public Health Service Policy on Humane Care and Use of Laboratory Animals.

Antibodies. Nav channel antibodies have been described previously (Rasband et al., 1999a, 2003) and were a kind gift from Dr. James Trimmer (University of California, Davis, CA). Mouse monoclonal (Rasband and Trimmer, 2001) and rabbit polyclonal anti-Caspr antibodies were made against the same fusion protein as for previously characterized anti-Caspr polyclonal rabbit antibodies (Peles et al., 1997). In all cases, no staining above background was detectable in sections incubated with secondary antibody alone. Anti-neurofilament-M (NF-M) was obtained from Chemicon (Temecula, CA), anti-myelin basic protein from Sigma (St. Louis, MO) or Sternberger Monoclonals (Lutherville, MD), and anti-peripherin from Chemicon.

Immunostaining. Six adult (3-4 months old) F1 mice were anesthetized by intraperitoneal pentobarbital. To preserve antigenicity for the antibodies used in this study, fixation with $4 \%$ paraformaldehyde in $0.1 \mathrm{M}$ phosphate buffer was limited to a $45 \mathrm{~min}$ period after the cochleas were perfused through the round window. The tissues were then rinsed with buffer and decalcified for $5 \mathrm{~d}$ (Whitlon et al., 2001). Because antigenicity of the Pan Nav antibody was significantly compromised by decalcification, this step was either omitted or limited to $2 \mathrm{~d}$. The brain and cochlea were cryoprotected with 10,20 , and $30 \%$ sucrose steps and were frozen at $-70^{\circ} \mathrm{C}$ overnight before sectioning at $15 \mu \mathrm{m}$ on a Hacker Instruments (Fairfield, NJ) cryostat. Sections were collected on SuperFrost/plus glass slides (Fisher Scientific, Houston, TX). Immunostaining was performed within 2-3 d of sectioning. Sections were blocked with $10 \%$ normal goat serum and $0.3 \%$ Triton X-100 in $0.1 \mathrm{~m}$ phosphate buffer for $2 \mathrm{~h}$, followed by overnight incubation with the primary antibody. The next day, after four 5 min washes, Alexa 488-conjugated secondary antibody (Molecular Probes, Eugene, OR) was used to detect rabbit polyclonal antibodies. Alexa 594-conjugated (Molecular Probes) secondary antibodies were used for visualization of the mouse monoclonal antibodies. After four 5 min rinses, the sections were mounted in Vectashield medium (Vector Laboratories, Burlingame, CA), coverslipped, and viewed on a fluorescent microscope equipped with a cooled CCD camera (Microimager II; Q-Imaging, Burnaby, Canada). Stacks of images were collected from the area of interest using a Z-capture program (Northern Eclipse version 6; Empix, Mississauga, Canada). In some cases, digital images were captured by using a Zeiss (Thornwood, NY) Axioskop 2 fluorescence microscope, fitted with a Hamamatsu (Bridgewater, NJ) ORCA-ER camera. $\mathrm{Z}$-stacks of images were collected at $0.2 \mu \mathrm{m}$ intervals, and the resulting stacks were deconvolved by interative restoration with the Volocity (Lexington, MA) software package.

Computational model. Neuronal modeling and simulations were performed with NEURON 5.6 by using a fixed time step of $25 \mu \mathrm{s}$ (12.5 $\mu \mathrm{s}$ in supplemental Fig. S3, available at www.jneurosci.org as supplemental material). The morphology of the type II ganglion cell was based on an illustration of an HRP-labeled cell by Berglund and Ryugo (1987, their Fig. 2). A high-resolution scan was first converted to Neurolucida format by using Neuron_Morpho plug-in (Dr. Giampaolo D’Alessandro, University of Southampton, Southampton, UK) for NIH ImageJ, and then the Neurolucida file was converted to NEURON format by using Neuron Morphology and Conversion Tool (CVAPP; Dr. Robert Cannon, University of Edinburgh, Edinburgh, UK). In the final form, the model con-
Table 1. Detailed geometry of the model neuron drawn in Figure $6 \mathrm{~A}$

\begin{tabular}{lcc}
\hline Name of the segment & Length $(\mu \mathrm{m})$ & Average diameter $(\mu \mathrm{m})$ \\
\hline Central axon, axon_C (distal part) & 272.5 & 0.547 \\
Central axon, axon_C (proximal part) & 53.8 & 0.830 \\
ISC & 18.3 & 1.064 \\
Central axon-soma junction & 6.4 & 1.272 \\
Soma & 15.5 & 10.230 \\
Peripheral axon-soma junction & 6.5 & 0.966 \\
ISP & 21.2 & 0.810 \\
Peripheral axon, axon_P (proximal part) & 30.2 & 0.768 \\
Peripheral axon, axon_P (distal part) & 134.2 & 0.481 \\
Recepto-neural segment (proximal part) & 100.8 & 0.528 \\
Recepto-neural segment (distal part) & 233.9 & 0.815 \\
\hline
\end{tabular}

Proximal and distal refer to proximity to the soma.

sisted of 54 compartments with an average length of $16.7 \pm 13.4 \mu \mathrm{m}$. The long and short axes of the cell body were set to 15 and $12 \mu \mathrm{m}$, respectively, based on diameters reported by Romand and Romand (1987). The diameters of the central and peripheral processes at the soma junction point were set to 1.02 and $0.91 \mu \mathrm{m}$, respectively. These, and the diameters of all other axonal segments (Table 1), were set to comply with measurements performed in adult mice by Berglund and Ryugo (1987) or in the present material. In the standard condition, the specific intracellular resistance $\left(R_{\mathrm{i}}\right)$, specific membrane resistance $\left(R_{\mathrm{m}}\right)$, and specific membrane capacitance $\left(C_{\mathrm{m}}\right)$ were uniform and set to $70 \Omega / \mathrm{cm}, 50 \mathrm{k} \Omega / \mathrm{cm}^{2}$, and $1 \mu \mathrm{F} / \mathrm{cm}^{-2}$, respectively. Hodgkin-Huxley type sodium $\left(g_{\mathrm{Na}}\right)$ and potassium channels $\left(g_{\mathrm{Km}}\right.$ and $\left.g_{\mathrm{Kv}}\right)$ were modeled as described previously (Mainen and Sejnowski, 1996), with uniform densities set to 120, 70, and $60 \mathrm{pS} / \mu \mathrm{m}^{2}$, respectively, in all compartments, including the cell body. We chose $g_{\text {na }}$, distributed uniformly at $120 \mathrm{pS} / \mu \mathrm{m}^{2}$, to provide the background level of sodium channel density. In this arrangement, each neuronal compartment, including the cell body, is capable of producing a sodium AP that overshoots zero by $>20 \mathrm{mV}$ during direct current injection (data not shown) or synaptic conductance change. Because the model was not required to produce high-frequency output, the potassium channels for shaping firing properties were not considered. To match the immunostaining patterns, additional sodium channels ( $g_{\text {nach }}$, $g_{\text {naf }} g_{\text {naxn }}$, and $\left.g_{\text {nahh }}\right)$ were inserted (one at a time) on top of the sodium channel background level in three critical sites (hot spots). The Hodgkin-Huxley type sodium channels $\left(g_{\text {nach }}, g_{\text {naf }}, g_{\text {naxn }}\right.$, and $\left.g_{\text {nahh }}\right)$ were modeled as described previously by Wang et al. (1998), Traub et al. (2003), Migliore et al. (2004), and Hodgkin and Huxley (1952), respectively. All channel mechanisms used in the present study were obtained from the web-accessible Model DB (Hines et al., 2004) and implemented without modification, except $g_{\text {naxn }}$, in which parameter sh (threshold) was set to $0 \mathrm{mV}$. APs in the recepto-neural segments were initiated by using the AlphaSynapse built-in function of NEURON with the onset, time constant $(\tau)$, synaptic conductance $\left(g_{\max }\right)$, and reversal potential (e) set to $50 \mathrm{~ms}, 5 \mathrm{~ms}, 3 \mathrm{nS}$, and $0 \mathrm{mV}$, respectively, unless otherwise specified. The terms $g_{\mathrm{Na}}$ and $g_{\mathrm{Nabar}}$ are used interchangeably in the text and have the same meaning, i.e., maximum specific sodium channel conductance. The present study has focused on the initiation of single APs. The possible contribution of Nav channels in the initiation and maintenance of high-frequency responses (Wang et al., 1998) was not investigated.

\section{Results}

In the organ of Corti, the afferent axons of type I and type II ganglion cells, as well as efferent fibers, are distinguished by their relative diameters, their positions in the tunnel of Corti, their branching patterns, and their innervation targets (Fig. 1A,B) (Berglund and Ryugo, 1987; Romand and Romand, 1987; Brown and Ledwith, 1990). In the osseous cochlea, likewise, there are a number of structural features that distinguish these neurons and their processes, e.g., myelination and relative diameters. Thus, each class of axon forms an anatomically distinct pathway that 

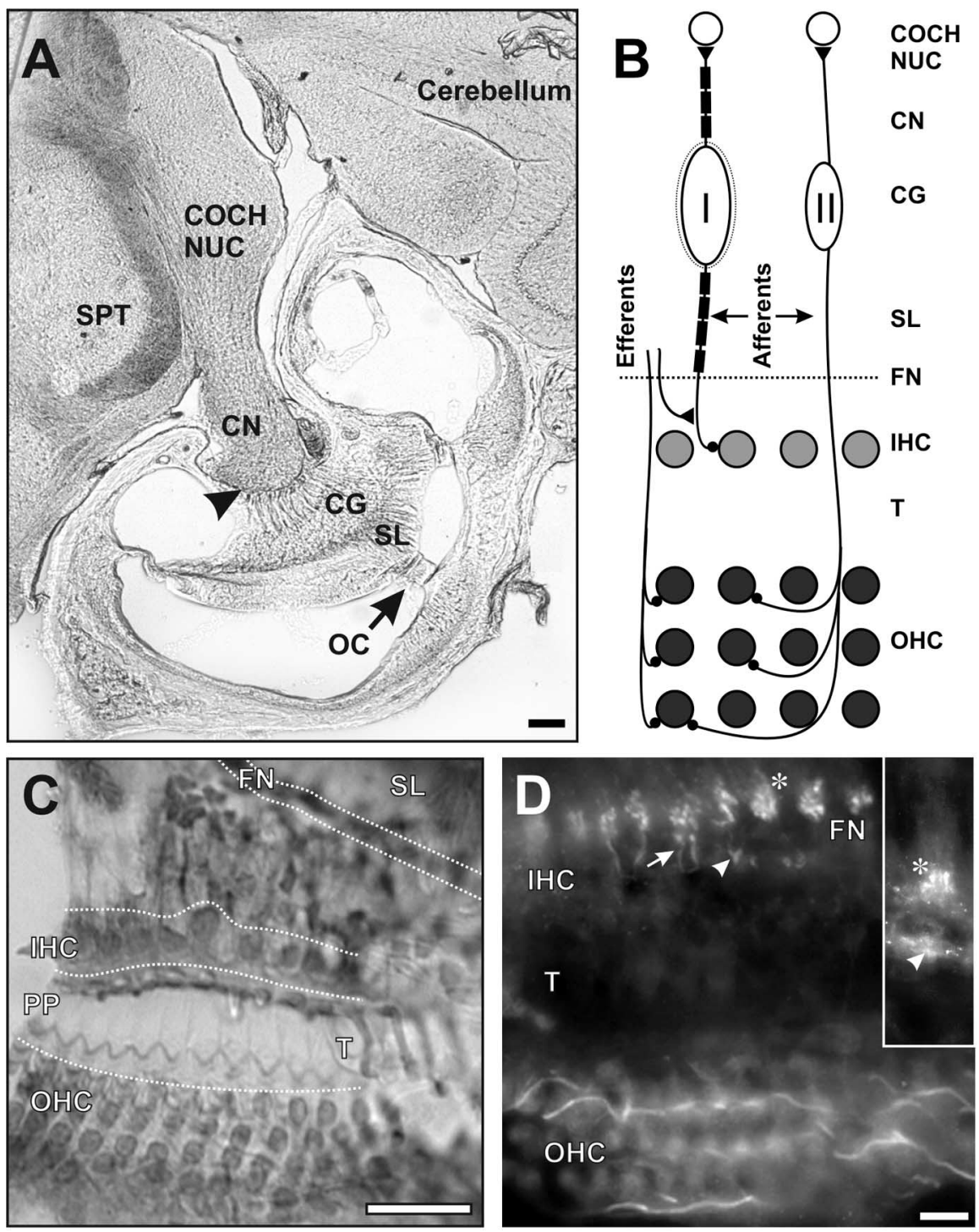

Figure 1. The auditory pathway. $A$, Low-magnification photomicrograph showing the relationships of the organ of $\mathrm{Corti}(\mathrm{OC})$, spiral lamina (SL), cochlear ganglion (CG), cochlear nerve (CN), and cochlear nucleus (COCH NUC) at the level of the basal coil of the cochlea. The arrowhead indicates the Schwann cell-oligodendroglial border. SPT, Spinal trigeminal nucleus. B, Scheme of cochlear innervation. Afferent fibers from myelinated type I ganglion cells innervate individual inner hair cells (IHC) in a single row in OC. Afferents from unmyelinated type Il ganglion cells cross the tunnel of Corti ( $T$ ) to innervate groups of outer hair cells (OHC), which are arranged in three rows. Both types of ganglion cells project to the cochlear nucleus. The efferent fibers arise in the brainstem and project to hair cells or their afferent endings in a complicated pattern, which is simplified for clarity in the diagram. All fibers enter and leave the $\mathrm{OC}$ through the $\mathrm{FN}$. $\mathrm{C}$, Horizontal section showing three rows of $\mathrm{OHCS}$, the phalangeal processes (PP) covering the tunnel, and one row of IHCS. D, In a plane below the IHCs, Nav1.6 is in the afferent endings (arrowhead) beneath the unlabeled IHC bases. Also stained are the afferent radial fibers (arrow) leading through the FN to their first heminodes $\left({ }^{*}\right.$ ), which are intensely labeled. On the outer side of the tunnel, at the bottom of the field, in a plane beneath the $\mathrm{OHCs}$, the afferent fibers of the outer spiral bundle are intensely stained as they run longitudinally. Inset, In another plane of focus, there is intense labeling of afferent IHC endings (arrowhead) and the first heminodes ( ${ }^{*}$ ). Scale bars: $\boldsymbol{A}, 0.2 \mathrm{~mm} ; \boldsymbol{C}, 25 \mu \mathrm{m} ; \boldsymbol{D}$ (for $\boldsymbol{D}$, inset), $10 \mu \mathrm{m}$.

can be reliably identified in histological preparations without recourse to markers and double staining.

To begin the search for candidate spike generators, we surveyed the entire cochlea by immunostaining with an antibody which recognizes all known neuronal voltage-gated $\mathrm{Na}^{+}$channels (Pan Nav) (Fig. 2A). High densities of Nav channels were detected at several locations throughout the pathways of the cochlear neurons. For example, in type I ganglion cells, Nav channels were clustered at the heminodes adjacent to the foramina nervosa (FN) (Fig. $2 B$, red) and at all subsequent nodes (Fig. $2 C-E$, red); these Nav channel clusters were flanked by immuno- staining for Caspr (Fig. 2C-E, green), a cell adhesion molecule that is part of the paranodal axo-glial junction. The myelinated cell bodies of type I ganglion cells were surrounded by Caspr immunostaining, but no Nav channel immunoreactivity was seen on the soma. In addition to the patterns described above, Pan Nav immunostaining was also present in the unmyelinated axons of the cochlea (data not shown), including the thinnest processes in the spiral lamina, consistent with type II ganglion cell afferents. However, Pan Nav staining intensity was sometimes weaker than that seen with the other Nav channel antibodies, because this antibody was very sensitive to the degree of fixation needed to preserve the delicate structures of the cochlea. Therefore, in the remainder of this study, we used the subtype-specific anti-Nav1.2 and anti-Nav1.6 antibodies, whose epitopes are much less sensitive to fixation, to define spike generators in the cochlea.

\section{Nav channel clusters in the axons and endings from type I cochlear ganglion cells}

The bulk of the neural activity coding for sound is produced by the inner hair cells, and this is transmitted at high firing rates by type I ganglion cells. Therefore, we first examined the spike generator of the type I ganglion cell in the afferent axons innervating the bases of the inner hair cell bodies (Fig. $1 B$ ). The first hypothesis we considered was that the location would be in the afferent ending itself or the most peripheral portion of the axon, i.e., the recepto-neural segment.

Within the organ of Corti, all axons are unmyelinated. As seen in horizontal sections parallel to the organ of Corti, the afferent fibers from the type I ganglion cell innervate the single row of inner hair cells (Figs. $1 B, C$, IHC), whereas the distal, preterminal portions of the axons (the recepto-neural segments) penetrate the $\mathrm{FN}$, in which the first heminodes are located. Nav1.6 was localized in the endings (Fig. $1 D$ and inset, arrowhead) and in the short recepto-neural segments of the thin radial afferent axons just beneath each inner hair cell (Fig. $1 D$, arrow).

At the first heminodes, robust staining for Nav1.6 was detected just within the foramina nervosa of the spiral lamina (Figs. $1 D$ and inset, asterisk; $2 F, G$, asterisk in boxed region). Heminodes were identified by using anti-Caspr, an axonal marker of the paranodal axo-glial junction, in which myelination begins. Caspr appeared between the Nav1.6 cluster and the beginning of the myelinated fiber layer of the spiral lamina (Fig. 2G, inset, arrow). Nav1.6 was present in high densities at nodes of Ranvier within the cochlear nerve, in regions both central and peripheral 
to the ganglion cell bodies (Fig. $2 H, I$ ). A similar pattern of nodal staining for Nav1.6 continued in the central nerve root past the Schwann cell-glial junction (data not shown). Axons in the spiral lamina also showed the punctuated distribution of Nav1.6 at nodes (Fig. 2G, arrowhead).

In contrast to Nav1.6, immunostaining for Nav1.2 was not detected in the radial afferents, in their endings, or in their axons in the spiral lamina, cochlear ganglion, or cochlear nerve (data not shown). Nav1.2 immunostaining of type I ganglion cell bodies was not detected. Thus, Nav1.6 appears to be the predominant channel found in processes of type I ganglion cells. Its distribution is consistent with the location of spike generation in the receptoneural segment and first heminode.

\section{How does the action potential rapidly and reliably traverse the ganglion cell body?}

The cochlear ganglion cell is a bipolar neuron, which consists of a large perikaryon with peripheral and central axons. This configuration presents a challenge to the rapid, efficient, and reliable propagation of APs, because the large cell body may act as a current sink attributable to the dramatic decrease in impedance. This would require a greater ionic current to sustain membrane depolarization and AP propagation. In the case of the type I ganglion cell, one feature that could compensate for this is the partial myelination of the cell body, including so-called "loose" myelin and sites of close apposition between the neuronal membrane and the loose myelin, first described in the rat by Rosenbluth (1962) and in the mouse by Romand and Romand (1987). A more eclectic mechanism, applicable to both type I and type II ganglion cells, would be the strategic location of Nav channels at or near the cell body to boost the current density.

When the ganglion cells were immunostained for either Pan Nav or Nav1.6, there was little or no labeling of the neuronal cell bodies (Figs. 2 D, E,I). The peripheral axon extending from the cell body tapers for a short distance before reaching the first node of Ranvier, whereas the corresponding part of the central process maintains the same diameter. In most cases, we found Nav1.6 at nodes of Ranvier flanking the type I ganglion cell bodies (Fig. $2 H, I$ ). However, there were also rare examples of ganglion cells with Nav1.6 clustered in high densities on the initial segments of the ganglionic axons (Fig. $2 M, N$, arrows). In these cases, both the peripheral (ISP) and central (ISC) initial segments were well
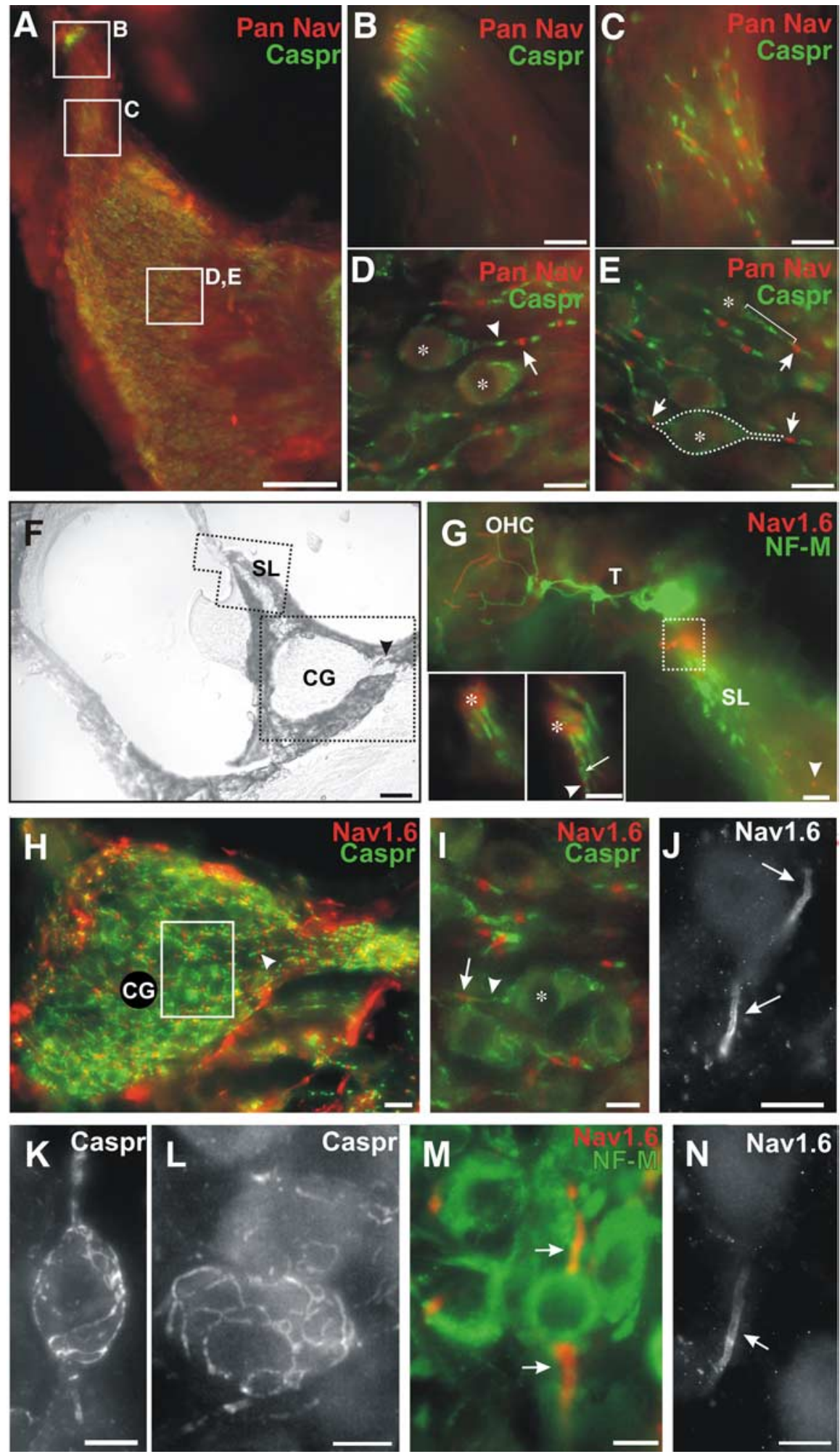

Figure 2. Pan Nav, Nav1.6, and Caspr in cochlear ganglion (CG) cells and fibers. A, Double immunostaining with Pan Nav (red) and Caspr (green) antibodies in a horizontal section showing sites from $\boldsymbol{B}-\boldsymbol{E}$. Scale bar, $100 \mu \mathrm{m}$. $\boldsymbol{B}$, The first heminodes at the foramina nervosa stain for Pan Nav; the paranodes stain for Caspr. $C$, In the spiral lamina, Pan Nav at the nodes of Ranvier and Caspr at the paranodes are consistently labeled. $\boldsymbol{D}, \boldsymbol{E}, \mathrm{In}$ the $\boldsymbol{G}$, the nodes of Ranvier are consistently labeled for Pan Nav, including those (arrows) that flank type I ganglion cell bodies, whereas the loose myelin around the cell bodies $\left(^{*}\right)$ and paranodes are stained for Caspr (arrowheads, bracket). In $\boldsymbol{E}$, a type I ganglion cell body out of the plane of focus is outlined to show the relationship of the central (right arrow) and peripheral (left arrow) nodes, which are stained for Pan Nav. Scale bars: $\boldsymbol{B}-\boldsymbol{E}, 10 \mu \mathrm{m}$. $\boldsymbol{F}$, Cross section from the basal turn showing the bony spiral lamina (SL), $(\mathrm{G}$, and central root of the cochlear nerve (arrowhead). Scale bar, $50 \mu \mathrm{m}$. $\boldsymbol{G}$, Polygonal field indicated in $\boldsymbol{F}$, showing the tunnel (T), outer hair cells (OHC), and SL, labeled for NF-M and Nav1.6. The first heminode (box in SL) is heavily labeled for Nav1.6 and less visibly for NF-M, whereas the NF-M-labeled myelinated nerve fibers runout of the field centrally toward the CG. Nodes of Ranvier are positive for Nav1.6 (arrowhead). (Figure legend continues.) 
stained, usually for a distance of 10-15 $\mu \mathrm{m}$ (Fig. $2 N$ ). Because they do not conform to strict criteria for either type I or type II ganglion cells (described below), we suggest that these other cells represent varieties of type I ganglion cells or type III ganglion cells, as described previously (Romand and Romand, 1987).

In the case of the type I ganglion cell, Caspr was present in a complex arrangement of tangled, web-like processes that swirled around the surfaces of the ganglion cell bodies in patterns reminiscent of the fine structure of loose myelin, first described in the rat by Rosenbluth (1962) and in the mouse by Romand and Romand (1987) (Fig. $2 K, L$ ). In contrast, Nav1.2 was not detected at any of the above sites (data not shown).

\section{Navl.6 channel clusters in type II ganglion cells}

Each type II ganglion cell typically innervates many outer hair cells spread over a relatively long distance, up to half a cochlear turn (Fig. $1 B$ ). Their axons are unmyelinated, including the outer spiral fibers, which cross the floor of the tunnel and course in the direction of the basal turn beneath the outer hair cells. Centrally, their axons are very thin, often $<0.5 \mu \mathrm{m}$ in diameter, and most likely have low firing rates, which could support a modulatory role in central auditory processing. We considered the possibility that Nav subtype expression in the more slowly conducting, unmyelinated type II ganglion cells might differ from that of the myelinated type I cells. Furthermore, without loose myelin surrounding the cell bodies of type II ganglion cells, the localization of Nav channels might be different than in the more abundant and myelinated type I ganglion cells.

In fact, the outer spiral fibers from the type II ganglion cells were well stained for Nav1.6 beneath the outer hair cells and along their spiral course, in which they could be traced through different focal planes (Figs. $3 A^{\prime}, A^{\prime \prime}, A^{\prime \prime \prime}, B$ ) (supplemental Videos $\mathrm{V} 1, \mathrm{~V} 2$, available at www.jneurosci.org as supplemental material). There was intense labeling of the endings at the bases of the outer hair cells (Fig. 3A', arrows). This staining was continuous throughout the recepto-neural segments of the axons as they joined the outer spiral bundle (Fig. $3 A^{\prime \prime \prime}$, arrow) and crossed the tunnel floor (Fig. $3 C$, arrows). The tunnel-crossing fibers from the outer spiral bundle were labeled with Nav1.6, but the axonal diameters $(0.5 \mu \mathrm{m})$ were much reduced there compared with the axons beneath the outer hair cells $(0.8-1.0 \mu \mathrm{m})$. In contrast, immunostaining for Nav1.2 was never seen in the type II afferents, neither on the floor of the tunnel nor in the outer spiral bundle axons or their endings.

Type II ganglion cell bodies are not always distinguishable from type I on the basis of light microscopic morphology. However, by using criteria described for the mouse (Berglund and

(Figure legend continued.) Insets (two focal planes), heminodes $\left(^{*}\right)$ and nodes of Ranvier (arrowhead) are labeled for Nav1.6 (red). Caspr (green) is labeled at the paranode of the heminodes and flanking nodes (arrow). Scale bar, $10 \mu \mathrm{m}$. $\boldsymbol{H}$, In a higher-power field (from $\boldsymbol{F}$ ) of the C $G$ and nerve root, Nav1.6 staining is present in the axons at nodes (arrowhead), bordered at the paranodes by Caspr. Nonspecific immunoreactivity (red) appears in the bony capsule around CG; this is commonly seen in cochlear immunohistology. Scale bar, $25 \mu \mathrm{m}$. I, Example of a type IGC from the preceding panel. The cell body $\left(^{*}\right)$ and central paranode (arrowhead) are outlined by immunostained Caspr up to the first node of Ranvier (arrow), which is stained for Nav1.6.J, Both central and peripheral initial segments of a type II cell are immunostained for Nav1.6 in heavy clusters (arrows), which increase progressively away from the cell body and stop sharply at a distal point. $\boldsymbol{K}, \boldsymbol{L}$, Higher magnification of type I C cells, surrounded by a Caspr-stained lacework, presumably associated with myelin or loose myelin. $M, N$, Initial axon segments of putative type III CG cells (arrows). In both the central and peripheral initial segments, Nav1.6 colocalizes with neurofilament-M $(\boldsymbol{M})$. Scale bars: $I-N, 10 \mu \mathrm{m}$.
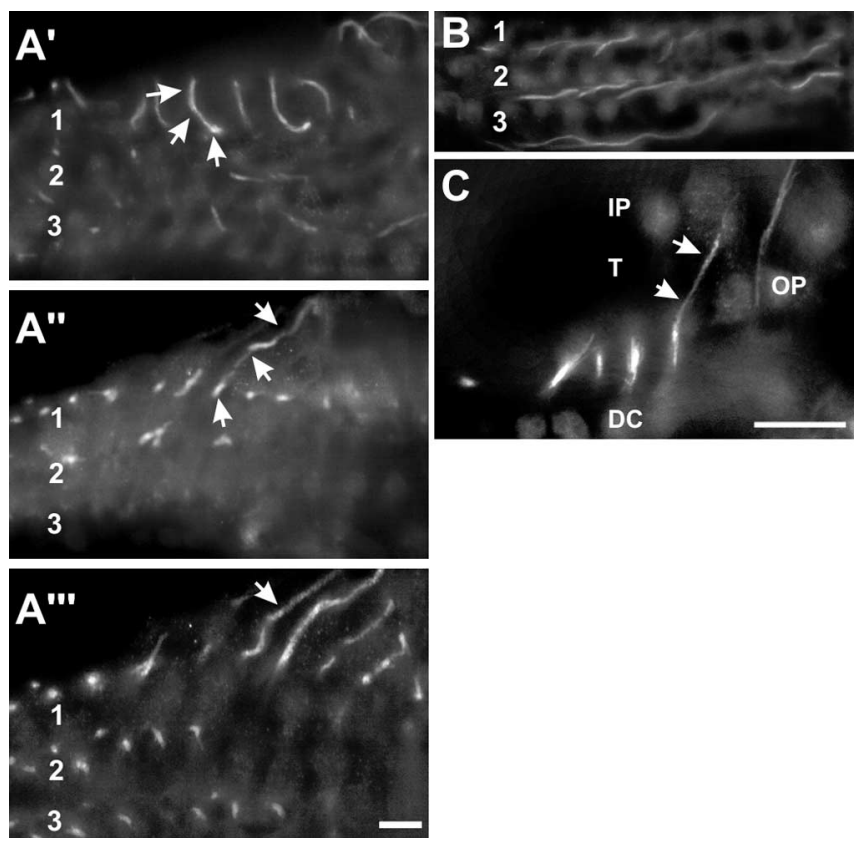

Figure 3. Nav1.6 tracks type II afferent innervation of outer hair cells (OHCs). $\boldsymbol{A}^{\prime}$, In a horizontal plane, just below the $\mathrm{OHCs}$, the afferent endings are labeled (arrows) in row 1. Also stained are preterminal portions of outer spiral fibers. $\boldsymbol{A}^{\prime \prime}$, The same location in a deeper plane shows an immunopositive afferent curving down to enter the outer spiral bundle (arrows). $A^{\prime \prime \prime}$, Still deeper beneath the $\mathrm{OHCs}$ are four afferent fibers in the outer spiral bundle (arrow). $\boldsymbol{B}$, In a plane below the preceding (section from Fig. 1D), the afferent outer spiral fibers are labeled along their entire lengths beneath the three rows of $\mathrm{OHCS}(1,2,3)$. C, Immunopositive outer spiral fiber (arrows) descends and crosses the tunnel floor (T). DC, Deiters cells; OP, outer pillar cell body; IP, inner pillar cell body. Scale bars, $10 \mu \mathrm{m}$.

Ryugo, 1987), we could identify a number of these cells in the peripheral (lateral) region of the ganglion. Briefly, these cells were distinguished from type I by an unmyelinated body that was often eccentric with respect to the central and peripheral processes (Fig. $1 \mathrm{~B}$ ). Within the cochlear ganglion, Nav1.6 labeling of type II ganglion cells was restricted to their peripheral and central initial segments (Fig. $2 \mathrm{~J}$, arrows). These processes were equal in diameter and maintained the same thickness for a distance of $20 \mu \mathrm{m}$ from their origins. Usually, the central process decreased greatly in diameter after a distance of 20-30 $\mu \mathrm{m}$. The criteria for this identification were verified in sections stained with an antibody to peripherin, which stained the type II cell bodies and the outer spiral fibers but not type I afferents (data not shown). Antibodies against neurofilament-M (Figs. 2G, 4A) and Kv1.2 (data not shown) stained both types of axons throughout the cochlea.

\section{Sodium channel localization in efferent fibers in the organ of Corti}

The efferent innervation of the organ of Corti is supplied by the olivo-cochlear fibers, which originate in the brainstem (Fig. $1 B$, efferents). These are not sensory fibers, but they function as a feedback pathway. Because their initial segments are in the brain, we did not expect to find evidence for a spike generator in the cochlea. The efferent fibers can be distinguished from the afferents at several points in their pathway. The efferents enter the cochlea via the vestibular nerve and take a tangential course in the intraganglionic spiral bundle, whereas the afferents course radially (except in the apical end) into the ganglion and enter the cochlear nerve. In the organ of Corti, many, if not all, of the efferents that supply the inner hair cell region, unlike the afferent 

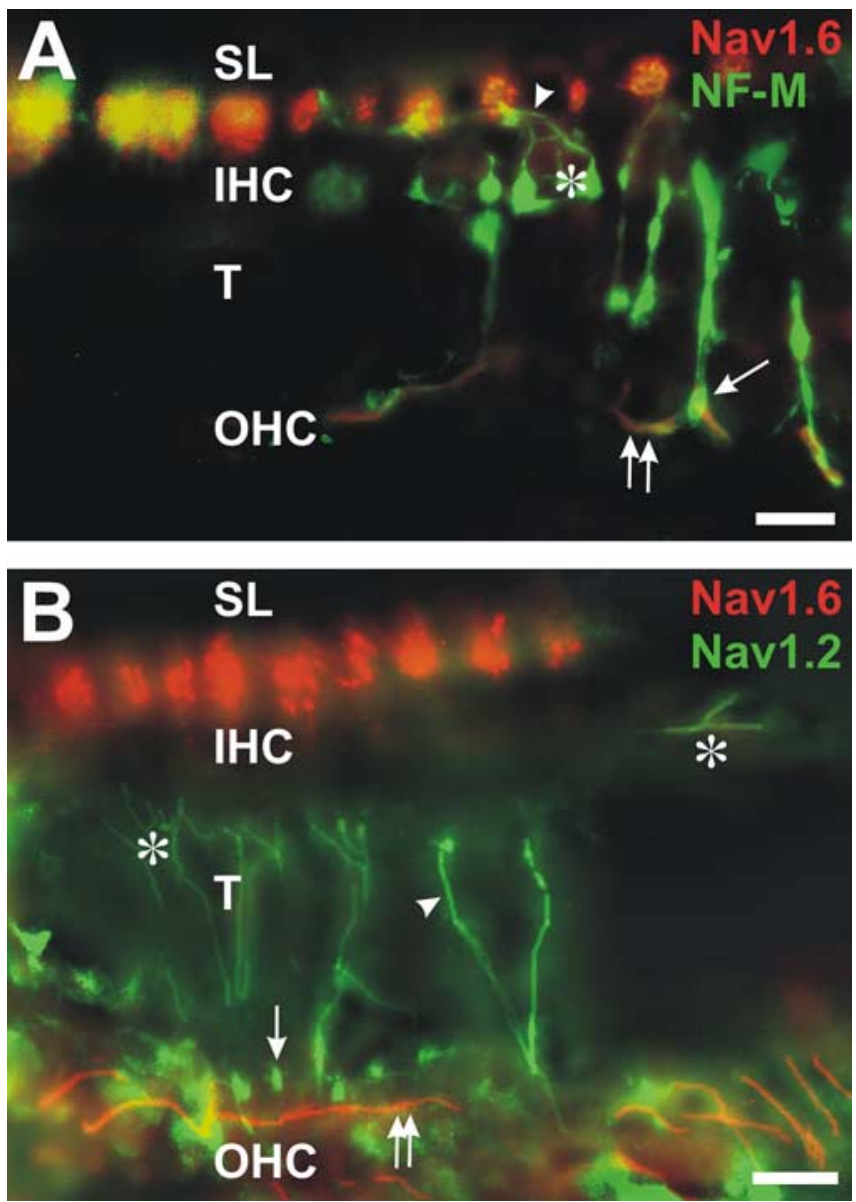

Figure 4. The cochlear efferent innervation uses Nav1.2 but not Nav1.6.A, An efferent fiber (arrowhead) and its ending $\left({ }^{*}\right.$ ) are labeled for NF-M beneath an IHC. Other efferent fibers cross the tunnel (T): one ends beneath an outer hair cell ( $\mathrm{OHC}$; arrow), in which it overlies an afferent ending labeled for Nav1.6 (yellow). Afferent fiber heminodes in the spiral lamina (SL) and afferent type Il fibers beneath $\mathrm{OHCs}$ (two arrows) are colabeled with Nav1.6 and NF-M. B, Some of the inner spiral bundle efferent endings beneath the inner hair cells $\left(\mathrm{IHC} ;{ }^{*}\right)$, the tunnel crossing efferents (arrowhead), and their endings (arrow) beneath row 1 of the $\mathrm{OHCs}$ are labeled for Nav1.2. Outer spiral fiber type Il afferents (two arrows) are labeled for Nav1.6 beneath the $\mathrm{OHCs}$ and at the heminodes in the SL. Scale bars, $10 \mu \mathrm{m}$.

fibers, course tangentially and synapse on the afferent fibers beneath the bases of the hair cell bodies. The efferent axons and their endings beneath inner hair cells were prominently stained for neurofilament-M (Fig. $4 A$, arrowhead, ${ }^{*}$ ).

The efferent endings, in contrast to the recepto-neural segments of ganglion cell axons, were not stained for Nav1.6 but were labeled for Nav1.2 (Fig. $4 B,^{*}$ ). The efferents in their definitive pathway cross the middle of the tunnel, and their endings, beneath the outer hair cells, contained neurofilament-M (Fig. $4 A$, arrow) and were clearly labeled for Nav1.2 (Fig. $4 B$, arrowhead, arrow) but not for Nav1.6. In the same sections, the type II afferents, which take a path distinct from the efferents by running on the floor of the tunnel and in the outer spiral bundle, were well stained for Nav1.6 but not Nav1.2 (double arrows).

\section{Nav channels in a deaf mutant, the quivering mouse}

The structure and molecular composition of nodes of Ranvier and axon initial segments are thought to be stabilized and maintained by ankyrin $\mathrm{G}$ in association with $\beta$-IV spectrin (Berghs et al., 2000; Komada and Soriano, 2002; Lacas-Gervais et al., 2004; Yang et al., 2004). Quivering mice have mutations in $\beta$-IV spec- trin and have aberrant clustering of Nav1.6 channels at nodes in the optic nerve (Yang et al., 2004) as well as hearing deficits (Parkinson et al., 2001). Previous experiments by us showed that overall levels of Nav channels in the brains of a specific allele of the quivering mouse, the $q v^{3 J}$ mutant, were normal and that Nav1.2 does not replace Nav1.6 at the disrupted nodes of Ranvier (Yang et al., 2004) (our unpublished results). Therefore, we considered the possibility that defective clustering of Nav1.6 channels in the cochlea could contribute to hearing loss in the mutants.

Although the light microscopic structure of the cochlea was generally unremarkable, the immunostaining for Nav1.6 revealed major abnormalities. There was little or no staining for Nav1.6 in the mutant cochlear epithelium, in the radial fibers and their endings beneath the inner hair cells, or in the outer spiral fibers and their endings beneath the outer hair cells, although these fibers were stained for neurofilament-M (compare Fig. $5 A, B$ with $1 D$ ). However, there was modest labeling for Nav1.6 of the first heminodes within the spiral lamina (Fig. $5 B, \mathrm{FN}$ ). In the spiral lamina and ganglion, many of the nodes were labeled for Nav1.6, but they were often elongated and disrupted (Fig. $5 F$ ) compared with the wild type (Fig. $5 E$ ). Some nodes were unstained for Nav1.6, although Caspr was clearly labeled (data not shown). The abnormal staining for Nav1.6 applies to the myelinated fibers of type I ganglion cells. We did not attempt to follow the myelinated fibers of the efferents in the intraganglionic spiral bundle. This result contrasts with the sciatic nerve, in which the nodes of Ranvier appear to be normal in these mice (Yang et al., 2004). In the cochlear ganglion, we detected clusters of Nav1.6 some distance from the cell body (Fig. 5C,D, arrowheads), presumably at the location of the ganglionic heminode, in which Caspr was also localized (Fig. 5D). We were unable to identify any initial segments labeled for Nav1.6, although this may reflect the sparse population of type II ganglion cells. Thus, Nav1.6 was not found in regions without adjacent myelin (i.e., initial segments and the recepto-neural segments), suggesting that Nav channels are no longer stabilized in the $q v^{3 J}$ mice and that the serious disruption in Nav1.6 localization may account for their hearing deficit.

A model for the generation of APs in the type II ganglion cell We chose to model the type II ganglion cell in the present study rather than type I, because the former, given its greater length and lack of myelination, should present the limiting case for successful AP propagation and thus provide a better opportunity to discover the potential role of sodium channels in these sensory neurons. We defined the outer spiral fiber of the type II neuron as an axon, consistent with the available light microscopic observations, including length, shape, and branching pattern, as well as immunostaining for neurofilament-M, peripherin, Kv1.2, and Nav channels. This definition is also supported by electron microscopy (Ginzberg and Morest, 1984 and many others). To elucidate the possible functional importance of Nav channels in the type II ganglion cell peripheral afferent axons, we considered the potential effects of adding channels to an otherwise weakly excitable membrane (see Materials and Methods).

In Figure $6 A$, we illustrate the morphology of the model neuron and the location we used for the synaptic input (syn.). In the absence of sodium channels (passive membrane), synaptic potentials of $\sim 40 \mathrm{mV}$ amplitude at the input site caused small $(\sim 6$ $\mathrm{mV}$ ) depolarizations of the soma (Fig. $6 B$, dashed lines and inset). This result was obtained with an electrotonically compact model neuron, characterized by low $R_{\mathrm{i}}(70 \Omega / \mathrm{cm})$ and high $R_{\mathrm{m}}$ 

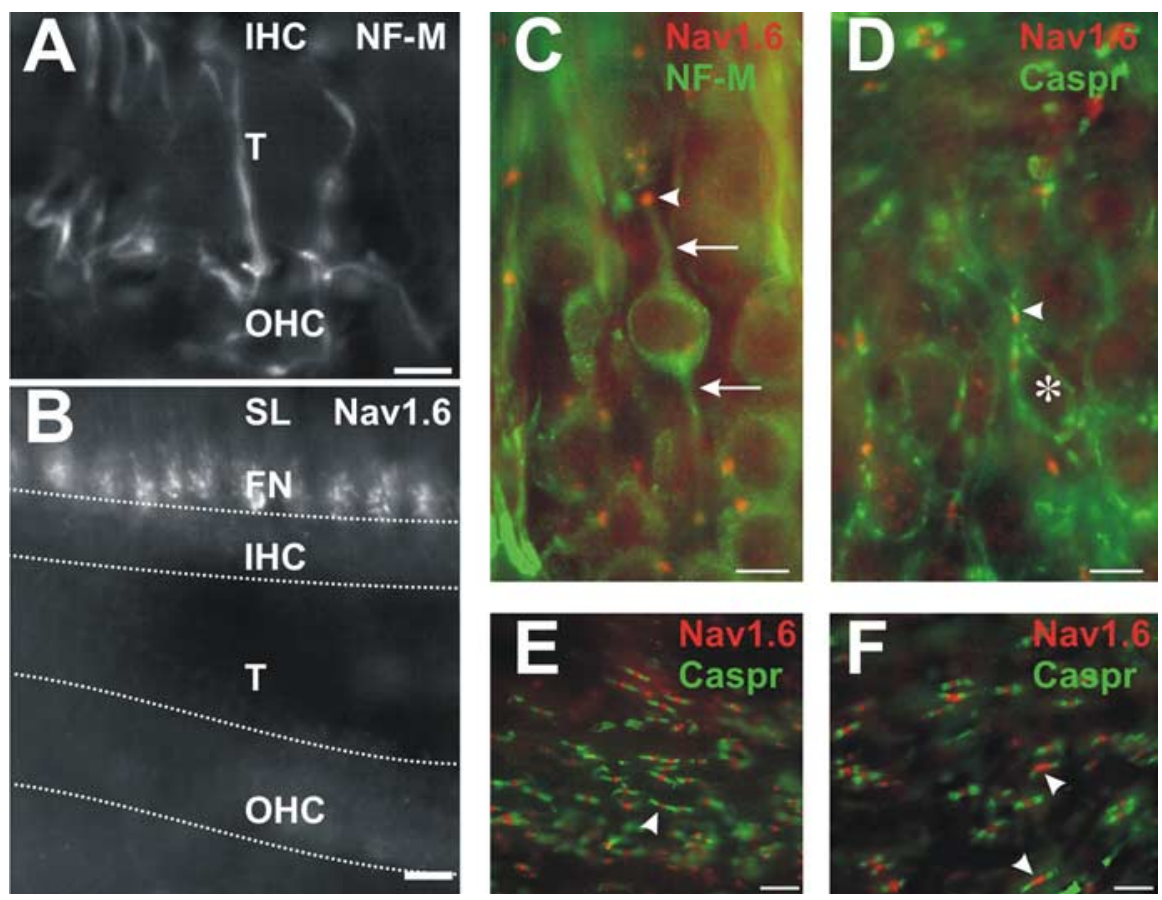

Figure 5. Nav1.6 localization is disrupted in quivering mice. $\boldsymbol{A}$, In the mutant, the afferent and efferent fibers innervating inner hair cells (IHC) and outer hair cells $(\mathrm{OHC}$ ) are present and labeled for NF-M. T, Tunnel. $\boldsymbol{B}$, Nav1.6 occurs at the first heminodes near the FN but not in the afferent fibers innervating hair cells. $\boldsymbol{C}$, In a mutant, a type I cochlear ganglion (CG) cell is labeled for NF-M (arrows). A small cluster of Nav1.6 can be detected on the central axon (arrowhead), presumably at the first flanking node of Ranvier. $\boldsymbol{D}$, In a mutant, a type I CG cell (*) initial segment is bordered by Caspr staining at the first flanking node of Ranvier on the peripheral axon (arrowhead). $\boldsymbol{E}$, In the spiral lamina (SL) of a wild-type mouse, the peripheral processes are stained for Nav1.6 at nodes of Ranvier (arrowhead). $\boldsymbol{F}$, In the corresponding locations from a mutant, Nav1.6 localization is disrupted, so that some nodes appear to be larger (arrowheads) compared with wild type. Scale bars, $10 \mu \mathrm{m}$.

$\left(50 \mathrm{k} \Omega / \mathrm{cm}^{2}\right)$. In the neurocomputational literature, a range for $R_{\mathrm{i}}$ of $150-250 \Omega / \mathrm{cm}$ has been assumed (Anderson et al., 1999; Archie and Mel, 2000; Durstewitz et al., 2000; Rhodes and Llinas, 2001; Vetter et al., 2001). As expected from the cable equation, larger values for $R_{\mathrm{i}}$ and smaller values for $R_{\mathrm{m}}$ produced more pronounced attenuation of the hair cell synaptic potential (data not shown). In all subsequent modeling experiments, AP propagation was studied under the condition of low $R_{\mathrm{i}}$ and high $R_{\mathrm{m}}$. This was done to impose a maximum constraint on the significance of actively generated currents for signal propagation.

The entire neuron, including the cell body, was endowed with a uniform density of sodium and potassium channels (background level of excitability), as specified in Materials and Methods. The densities of the background voltage-gated sodium and potassium conductances were set in such a way that each neuronal compartment triggered a swift AP, whose amplitude overshot zero by at least $20 \mathrm{mV}$ (Fig. $6 \mathrm{~B}$, solid red line). However, despite the large amplitude (97.6 $\mathrm{mV}$, measured from baseline) and rather long duration (half-width of $1.42 \mathrm{~ms}$ ), the synaptically evoked AP failed to propagate from the recepto-neural segment (rec_neu) into the soma (Fig. 6B, solid black line). Because the densities of active membrane conductances were uniform throughout the entire neuron, the AP propagation failure was attributed to the sudden increase in diameter at the axon-soma junction point.

It has long been known that a geometrical incongruity can impose a substantial obstacle for propagation of regenerative potentials (Goldstein and Rall, 1974; Parnas et al., 1976). A traveling AP could perhaps overcome the impedance mismatch between the axon and the soma if the axon-soma transition were enriched with sodium conductance (Luscher and Larkum, 1998). However, introducing a 10 -fold higher density of sodium channels (hot spot) in the recepto-neural segment (Fig. 6C) or in either of the axon initial segments (Fig. 6D,E) was not sufficient to support AP propagation. Only when both central and peripheral axon initial segments (ISC and ISP) were rendered active would the synaptically evoked APs reliably propagate from the recepto-neural segment into the soma (Fig. 6F). Adding or removing sodium channels from the recepto-neural segment did not have a significant effect on the ability of APs to propagate through the axon-soma junction, as long as both axon initial segments were loaded with sodium conductance (data not shown). This is not to say that sodium channels in the recepto-neural segment have no role in the processing of the outer hair cell inputs.

The present modeling study revealed two important functions of the receptoneural hot spot. First, in the absence of this hot spot, the level of synaptic input $\left(g_{\max }\right)$ required to generate a nerve impulse in the recepto-neural segment was significantly higher (supplemental Fig. S1, available at www.jneurosci.org as supplemental material). Second, insertion of sodium channels in the recepto-neural segment dramatically reduced the AP peak latency, measured as a time interval between the onset of the synaptic potential and the peak of the somatic AP (supplemental Fig. S2 A, $B$, available at www.jneurosci.org as supplemental material). The effect on the somatic AP peak latency was entirely the result of the AP initiation process in the recepto-neural segment, and it was not attributable to a change in the AP velocity. In fact, the conduction velocity of the evoked AP was almost insensitive to the density of sodium channels in the receptoneural segment (supplemental Fig. S2C, available at www. jneurosci.org as supplemental material).

The modeling experiments presented so far establish that, in some cases, a single AP failed to propagate from the initiation site in the outer hair cell layer to the ganglion cell body (Fig. 6C-E), unless both peripheral and central axon initial segments were adequately endowed with sodium channels (Fig. $6 F$ ). We next examined the range of $g_{\mathrm{Na}}$ (sensitive range), in which our model exhibits this particular feature, i.e., a strong dependence on both axonal hot spots. Such a range would serve as a measure of the robustness of the model, the reliability of the results, and the validity of the conclusions laid out in Figures 6 and 8 .

The exploration of the sensitive range was performed with each one of the four different channel mechanisms ( $g_{\text {nach }}, g_{\text {naf }}$, $g_{\text {naxn }}$, and $\left.g_{\text {nahh }}\right)$, previously published by Wang et al. (1998), Traub et al. (2003), Migliore et al. (2004), and Hodgkin and Huxley (1952), respectively. The differences between these channel mechanisms are described in supplemental Figure S3 (available at www.jneurosci.org as supplemental material). The passive parameters, background excitability, and synaptic stimulation were as described for the standard conditions (see Materials and Methods). In the example shown in Figure 7, $A$ and $B$, additional Hodgkin-Huxley sodium channels $\left(g_{\text {nabar_hh }}\right)$ were inserted in 
the recepto-neural segment and in both initial segments (ISP and ISC) on top of the sodium channel background level. In this series of experiments, the receptoneural $g_{\text {nabar_hh }}$ was fixed at $1200 \mathrm{pS} / \mu \mathrm{m}^{2}$, whereas the $g_{\text {nabar_hh }}$ in both initial segments was varied to determine the minimum density of hh sodium channels that would permit propagation of single APs. Membrane potential transients were "recorded" from multiple sites along the recepto-neural segment (rec_neu), peripheral axon (axon_P), soma, and central axon.

Using this model, we gradually reduced the $g_{\mathrm{Na}}$ in both initial segments concurrently, until the synaptically evoked $\mathrm{AP}$ failed to invade the soma (Fig. 7A, heavy line, 928). Adding just $1 \mathrm{pS} / \mu \mathrm{m}^{2}$ to each initial segment allowed an AP to invade the soma (929). The lower boundary of the sensitive range, therefore, may be defined as the minimum density of sodium conductance $\left(929 \mathrm{pS} / \mu \mathrm{m}^{2}\right)$, distributed equally in both initial segments, which still supports the propagation of the spike (Fig. $7 A$, thin line, $C$, black bars). Conversely, the upper limit of the sensitive range is the minimum value of $g_{\mathrm{Na}}$, which, when applied to one initial segment alone, would effectively support AP propagation through the axon-soma transition (Fig. $7 B$, dashed line, $C$, gray bars). At this relatively high density of sodium conductance, an insertion of new sodium channels in the opposite initial segment had no effect on the outcome of the propagation (data not shown). From this point on, the model became insensitive to the distribution of sodium channels between any of the three hot spots. The absolute values for the lower and upper boundaries of the sensitive range are listed in Table 2.

Three important results emerged from these experiments. First, regardless of the channel mechanism used, the propagation of an AP in all model neurons was very sensitive to the lack of sodium channels in either central or peripheral axon initial segment (Fig. 7C). Second, for forward (afferent) propagating APs, the ISP appears to play a slightly greater role than the ISC. In other words, the ISP requires less sodium conductance (dark gray bars) than the ISC (light gray bars) to do the same job. This feature was preserved in all model neurons, regardless of the sodium channel mechanism (Fig. 7C). Additional evidence for a slightly more effective role of the ISP came from measurements of the amplitude of failing APs in the cell body (Fig. $6 C-E$, horizontal line $\pi$ ). During the AP propagation failure, the ensuing peak depolarization of the soma was higher if sodium channels were inserted in the ISP (Fig. $6 E$ ) rather than the ISC (Fig. 6D). Third, multiple-site recordings from the proximal portion of the peripheral axon (Fig. 6A, axon_P) revealed that this is the region with the lowest safety margin for AP propagation (Fig. 7D). In this region, a severe attenuation of the traveling AP occurred, even when both initial segments were loaded

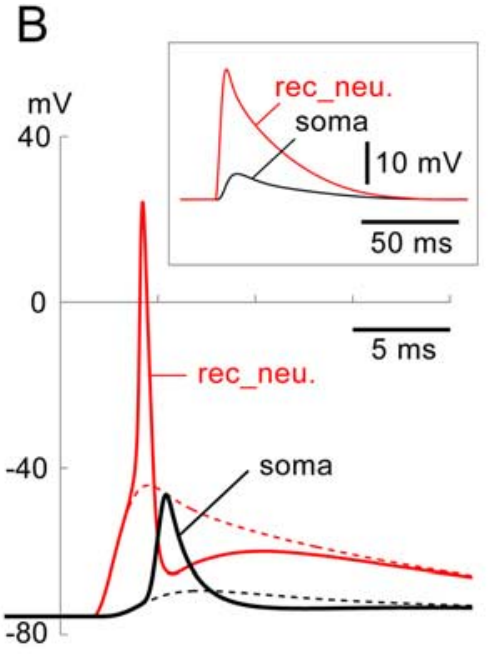
$\mathrm{E} \quad \mathrm{F}$

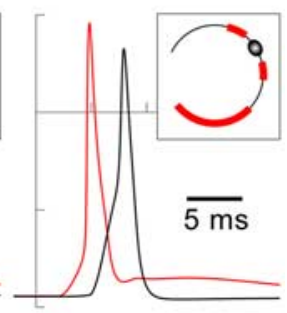

Figure 6. Modeling AP initiation and propagation in type II ganglion cells. $A$, The morphological model has six regions: (1) central axon (axon_C); (2) ISC; (3) soma; (4) ISP; (5) peripheral axon (axon_P); and (6) recepto-neural segment with six endings onair cells (syn.). The gray horizontal line marks the boundary between axon_P and the recepto-neural segment, just proxima recepto-neural region (solid red line) fails to invade the soma (solid black line) In the next sweep (dashed lines), sodium channels are removed from the entire neuron, and the same synaptic stimulation is repeated. Inset, The same sweep (dashed lines) shown spor, i.e., loaded with a uniform density of the Hodgkin-Huxley sodium conductance $\left(g_{\text {nabar_hh }}=1200 \mathrm{pS} / \mu \mathrm{m}^{2}\right.$ ) on top of the indicates the hot spots in the corresponding experiments. $\boldsymbol{D}, \boldsymbol{E}$, When a second hot spot is inserted in the ISC (D) or ISP $(\boldsymbol{E})$, an AP generated in the recepto-neural segment (red trace) fails to invade the soma (black trace). The horizontal line $\pi$ marks the amplitude of the peak somatic depolarization. $\boldsymbol{F}$, With all three of the hot spots loaded $\left(g_{\text {nabar hh }}=1200 \mathrm{pS} / \mu \mathrm{m}^{2}\right)$, the AP successfully invades the soma (black trace).

with sodium channels (Fig. 7E). However, if an AP failed in the region of low safety margin in axon_P, it was reinitiated in the strategically positioned ISP and ISC (Fig. $6 \mathrm{~A}$, inset). The characteristic double peak (Fig. 7E, arrow) consists of the failing first spike (Q) and the reflected second spike (R) and has been described in model neurons (Goldstein and Rall, 1974; Parnas et al., 1976) and, most importantly, in real neurons (Ramon et al., 1975; Antic et al., 2000).

\section{Discussion}

\section{Multiple voltage generators for cochlear ganglion cells} and fibers

We have localized Nav channel subunits Nav1.2 and Nav1.6 to different sites on cochlear neurons. The results are summarized in Figure 8. Previous studies have also shown these channels in distinct domains: Nav1.2 in unmyelinated axons and Nav1.6 at nodes of Ranvier (Gong et al., 1999; Boiko et al., 2001). However, Nav1.2 and Nav1.6 can colocalize at initial segments of retinal, hippocampal, and spinal neurons (Alessandri-Haber et al., 2002; 


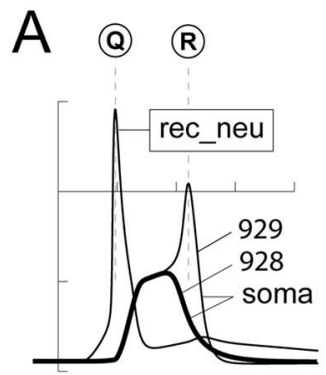

(Q)

$\mathrm{D}$
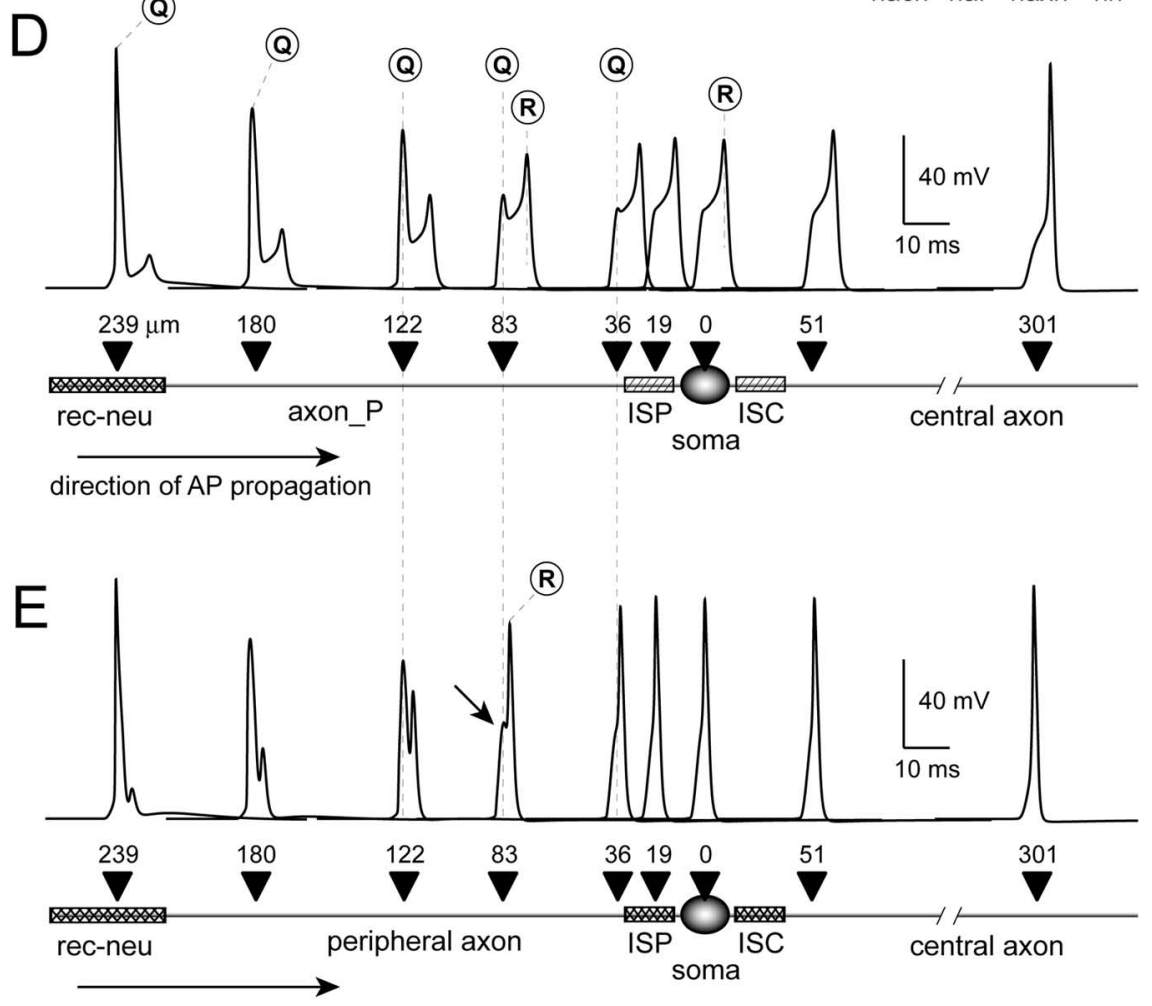

Figure 7. Parameter range (sensitive range) for AP propagation. $\boldsymbol{A}$, The "recording" from the recepto-neural segment (rec_neu is red dot in Fig. 6A, $407 \mu \mathrm{m}$ from soma) is superimposed on the somatic recordings (soma). In the first sweep (heavy line), when $g_{\text {nabar } \_h}$ in each initial segment (ISP and ISC) is set to $928 \mathrm{pS} / \mu \mathrm{m}^{2}$, an AP fails to invade the soma. In the second sweep (thin line), adding $1 \mathrm{pS} / \mu \mathrm{m}^{2}$ to each initial segment allows an AP to invade the soma, making $929 \mathrm{pS} / \mu \mathrm{m}^{2}$ the lower limit of the sensitive range. $\boldsymbol{B}$, At higher densities $\left(g_{\text {nabar_hh }}=1200 \mathrm{pS} / \mu \mathrm{m}^{2}\right)$ distributed equally in both initial segments, AP amplitude and peak latency of the somatic spike improve (solid lines). A sign of the failing axonal AP appears as a hump on the rising phase of the spike. The second sweep (dashed line) is an example in which channels are inserted in ISC alone at the minimal density ( $\left.g_{\text {nabar } n h}=1853 \mathrm{pS} / \mu \mathrm{m}^{2}\right)$ that permits invasion of the soma (upper limit of sensitive range). C, Simulations with four different channel mechanisms (nach, naf, naxn, and nahh) show similar sensitive ranges. Bars mark the normalized permissive channel density in the ISP (dark gray) or ISC (light gray) alone. Gray values are normalized with respect to $\mathrm{Na}^{+}$conductance, distributed equally between both initial segments (black bars). Absolute densities (in picosiemens per square micrometer) are in Table 2. D, With $g_{\text {nabar }}$ at $929 \mathrm{pS} / \mu \mathrm{m}^{2}$ in both initial segments (ISP, ISC), an AP barely invades the central axon. Multisite recordings reveal the transients in different neuronal compartments. Black triangles mark the recording sites on a schematic of a type II ganglion cell. Numbers are micrometers from cell body. Q marks the peak of the failing AP (hump potential). R marks the peak of the reinitiated (reflected) AP. $\boldsymbol{E}$, Same as $\boldsymbol{D}$, with $g_{\text {nabar }}$ hh at $1200 \mathrm{pS} / \mu \mathrm{m}^{2}$. Despite high channel density, a hump potential (arrow) persists in the region of low safety margin for AP propagation in the proximal part of the peripheral axon.

the thinnest parts of unmyelinated type II afferents, which were below threshold for reliable labeling.

Our results suggest that voltage generators, composed of clusters of Nav1.6, are located at central and peripheral axonal initial segments and nodes of Ranvier flanking the bipolar ganglion cell bodies and in their afferents within the receptor itself (recepto-neural segments) (Fig. 8). Spiking has been recorded from juxtaganglionic axons and may also appear in radial afferents beneath inner hair cells (Robertson, 1976; Russell and Palmer, 1986; Siegel and Dallos, 1986; Siegel, 1992). In the myelinated afferents, Nav1.6 at the first heminode could generate spikes, with subsequent transmission supported by Nav1.6 at nodes of Ranvier. The cochlear efferents may use Nav1.2 to support spiking in the organ of Corti and some other Nav channel for conduction of APs in more central parts.

\section{Nav1.6 channels in type I cochlear ganglion cells}

In the somatic sensory nerves, the spike generator has been assigned to the first node of Ranvier (Loewenstein and Ishiko, 1960). In contrast, we show here that the recepto-neural segment of type I ganglion cells has Nav1.6 at the very ending of the afferent axon beneath an inner hair cell and on the inner radial fiber up to and including the first heminode. Nav1.6 is also usually present at nodes of Ranvier flanking the ganglion cell body and in both peripheral and central axons in which they may facilitate transganglionic conduction. If Nav1.6 supports high firing rates, its multiple locations could promote discrete, rapid transfer of the output of each hair cell to the cochlear nucleus, in some cases by one-to-one connections (Morest, 1997; Young and Oertel, 2004).

Nav1.6 channels in type II ganglion cells Outer hair cells function by local mechanical influences on inner hair cell output (Nicholls et al., 2001; Young and Oertel, 2004). However, little is known about their physiology and function (Robertson et al., 1999). A type II ganglion cell typically innervates many hair cells over a long distance, up to half a cochlear turn. Each

Boiko et al., 2003; Garrido et al., 2003). The reasons for differential localization are uncertain, but some data suggest that Nav1.6 underlies resurgent sodium current, which may facilitate repetitive firing (Raman et al., 1997). However, phosphorylation and/or interacting proteins can modulate Nav channel properties (Isom et al., 1994; Cantrell and Catterall, 2001). Nav1.2 and Nav1.6 immunostaining accounted for most of the immunoreactivity seen with a pan-specific Nav channel antibody, except for group of hair cells innervated is displaced from the site at which their afferent fibers leave the organ of Corti by hundreds of micrometers compared with type I afferents at the same level (Fig. 8). Type II afferents in the outer spiral bundle are unmyelinated. Consequently, outer hair cell outputs could undergo delay and even decay compared with their type I counterparts.

Nav1.6 channels may support spike generation by type II afferent fiber endings beneath outer hair cells and along the outer 
Table 2. Minimal (permissive) $g_{\text {Nabar }}$ required for AP invasion of the cell body based on four different sodium channel mechanisms in three distributions

\begin{tabular}{llllll}
\hline \multicolumn{2}{l}{ Channel mechanism } & & \multicolumn{3}{l}{ Channel distributions } \\
\cline { 1 - 1 } Suffix & Source & & ISP alone & ISC alone & ISP + ISC \\
\hline nach & Wang et al. (1998) & & 2057 & 2442 & 1227 \\
naf & Traub et al. (2003) & & 2271 & 2870 & 1391 \\
naxn & Migliore et al. (2004) & & 507 & 786 & 333 \\
nahh & Hodgkin and Huxley (1952) & & 1692 & 1853 & 929
\end{tabular}

Values are expressed in picosiemens per square micrometer.

spiral fibers. The highly excitable recepto-neural segment could respond to small synaptic inputs from hair cells and effectively transmit the resulting APs out of the organ of Corti. The presence of Nav channels in the initial segments flanking the type II cell body suggests that these neurons can reliably transmit APs into the cochlear nucleus (Hurd et al., 1999; Benson and Brown, 2004). The speed and rate with which APs arrive in the cochlear nucleus would be slower than for type I ganglion cells, because the rest of the type II pathway consists of very thin, unmyelinated fibers.

Problem of the bipolar ganglion cell body

Cochlear ganglion cell bodies are situated in the middle of the axon. The resulting cable properties suggest that conduction velocity might decrease to the point of complete failure attributable to an impedance mismatch (Robertson, 1976; Mo et al., 2002), although this may be partially alleviated in type I ganglion cells by the loose myelin wrapping their somata (Rosenbluth, 1962; Romand and Romand, 1987). Ion channels in the perikaryal membrane may help compensate (Santos-Sacchi, 1993; Adamson et al., 2002; Szabo et al., 2002). However, we rarely saw clusters of Nav1.6 in the perikaryal membranes of either type I or type II ganglion cells. According to our computational model for type II ganglion cells, Nav1.6 channels clustered at the ganglionic initial segments should be able to generate sufficient $\mathrm{Na}^{+}$currents to compensate for the axon-soma impedance mismatch (Fig. $6 \mathrm{~F}$ ).

A striking feature of the type I ganglion cell is the fine, lacy network of axo-glial junctions around the ganglion cell body. Previous studies have shown that Caspr-containing sites of axoglial contact are important for ion channel localization and expression in retinal ganglion cell axons (Rasband et al., 1999a,b; Rios et al., 2003). Thus, we speculate that these lacy axo-glial networks may participate in regulating the kinds of Nav channels expressed in type I ganglion cells.

\section{Efferent fibers in the cochlea}

Nav1.2, but not Nav1.6, was detected in the unmyelinated portion of efferent axons in the sensory epithelium and their endings beneath inner and outer hair cells. This finding is consistent with reports of Nav1.2 expression in unmyelinated axons (Westenbroek et al., 1989). Nav1.2 channels may sustain slower firing rates than Nav1.6 (O'Leary, 1998; Herzog et al., 2003). The functional significance of the cochlear efferents is uncertain. The unmyelinated efferent pathway is part of a negative feedback circuit to the inner hair cells, which modulates the cochlear afferent response to acoustic amplitude changes over time (Liberman and Brown, 1986; Maison et al., 2003). The faster efferent pathway (crossed olivo-cochlear bundle) may shorten outer hair cells when acoustic intensity changes and would presumably require faster conduction (Brownell et al., 1985). These fibers are myelinated until entering the epithelium, but their content of Nav1.2 in the organ of Corti may refine their firing rates.

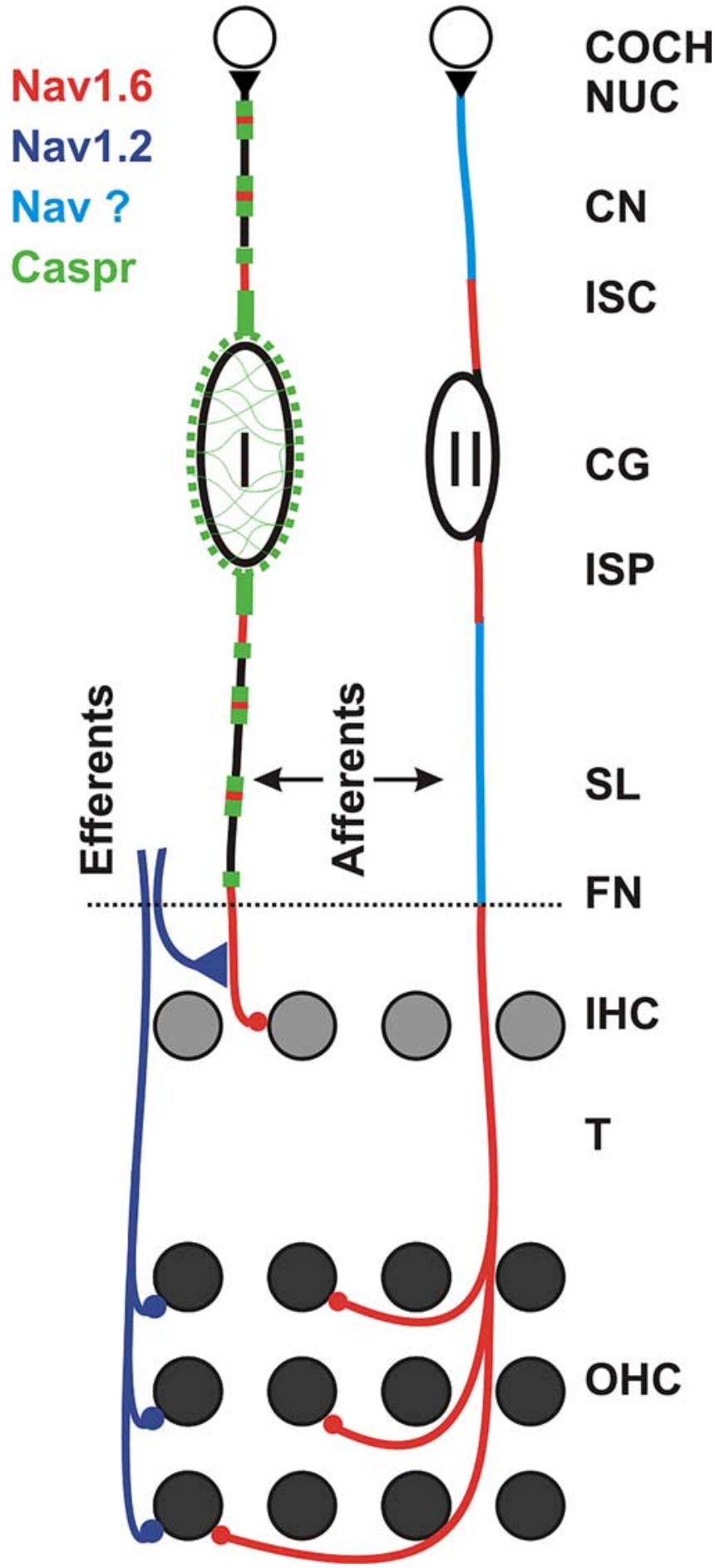

Figure 8. Voltage-gated sodium channels in cochlear nerve (CN) cells. Type I cochlear ganglion cells $(C G, I)$ provide rapid transfer of discrete auditory signals from individual inner hair cells (IHC) for precise spatiotemporal processing in the cochlear nucleus (COCH NUC) by the shortest route. To support this divergent processing at a high level of temporal precision, the afferent fibers from IHCs have Nav1.6 channels available for voltage generators on their terminals and axons in the organ of Corti, at the first heminodes just central to the $\mathrm{FN}$, at subsequent nodes of Ranvier and nodes flanking the cell bodies (I). Type II ganglion cells (CG, II) provide slower processing for many outer hair cells $(\mathrm{OHC})$ spread out over a longer distance. To support this convergent mode of processing in a temporally secure relationship to IHC activity, the afferent fibers from the $\mathrm{OHChave} \mathrm{Nav1.6} \mathrm{channels} \mathrm{over} \mathrm{their} \mathrm{entire} \mathrm{course} \mathrm{in} \mathrm{the} \mathrm{organ} \mathrm{of} \mathrm{Corti.}$ Both initial segments at the CGII cell body express Nav1.6, but it is uncertain what specific sodium channels occur at low density on the rest of the axon. The efferents use Nav1.2 in the organ of Corti. Caspr is expressed at the paranodes of type I fibers and in the myelinated layers around the CGI cell bodies. SL, Spiral lamina; T, tunnel. 


\section{Functional considerations of sodium channel organization in the cochlea}

Our simulations showed that the soma of the type II cell represents too much of an electrical load to ensure safe AP propagation from the outer hair cell layer to the brain (supplemental Fig. 4, available at www.jneurosci.org as supplemental material). To overcome the impedance mismatch, both the peripheral and central axon initial segments must provide additional current. The physiological role of the high density of sodium channels in the recepto-neural segment beneath outer hair cells (Fig. 8) is to lower the synaptic threshold (supplemental Fig. S1, available at www.jneurosci.org as supplemental material) and reduce the stimulus-to-AP latency (supplemental Fig. S2, available at www. jneurosci.org as supplemental material). The model suggests that all three regions of high Nav channel density play distinctive and important roles in auditory processing. This conclusion is further supported by the observation that the Nav channel clusters in $q v^{3 J}$ mice were defective in these three critical regions in both types of ganglion cells. $\beta$-IV spectrins are thought to play a role in the localization of Nav channels in the initial segment of axons and nodes of Ranvier (for a discussion, see Yang et al., 2004). Thus, the hearing deficit in these animals may reflect impairments in the initiation and propagation of APs in the cochlea. Together, our results suggest that precise control of the density and location of Nav channels in type I and II cochlear ganglion cells is important for their function.

In summary, bipolar cochlear ganglion cells contain Nav1.6 channels on the peripheral and central initial segments attached to their cell bodies, on the recepto-neural segments and endings beneath inner and outer hair cells, and at nodes and heminodes of their myelinated cell bodies and axons (Fig. 8). These results suggest that the two main types of ganglion cells, which innervate inner and outer hair cells, contain multiple spike generators. Nav1.6 channels may reduce the threshold and latency of signals generated in the recepto-neural segment. Furthermore, voltagegated sodium channels in the ganglionic initial segments or flanking nodes of Ranvier may compensate for the axon-soma impedance mismatch, which would otherwise compromise spike conduction. Thus, we propose that cochlear ganglion cells use strategically placed sodium channels to deliver action potentials to the cochlear nucleus in response to acoustic stimulation.

\section{References}

Adamson CL, Reid MA, Davis RL (2002) Opposite actions of brain-derived neurotrophic factor and neurotrophin-3 on firing features and ion channel composition of murine spiral ganglion neurons. J Neurosci 22:1385-1396.

Alessandri-Haber N, Alcaraz G, Deleuze C, Jullien F, Manrique C, Couraud F, Crest M, Giraud P (2002) Molecular determinants of emerging excitability in rat embryonic motoneurons. J Physiol (Lond) 541:25-39.

Anderson JC, Binzegger T, Kahana O, Martin KA, Segev I (1999) Dendritic asymmetry cannot account for directional responses of neurons in visual cortex. Nat Neurosci 2:820-824.

Antic S, Wuskell JP, Loew L, Zecevic D (2000) Functional profile of the giant metacerebral neuron of Helix aspersa: temporal and spatial dynamics of electrical activity in situ. J Physiol (Lond) 527:55-69.

Archie KA, Mel BW (2000) A model for intradendritic computation of binocular disparity. Nat Neurosci 3:54-63.

Benson TE, Brown MC (2004) Postsynaptic targets of type II auditory nerve fibers in the cochlear nucleus. J Assoc Res Otolaryngol 5:111-125.

Berghs S, Aggujaro D, Dirkx Jr R, Maksimova E, Stabach P, Hermel JM, Zhang JP, Philbrick W, Slepnev V, Ort T, Solimena M (2000) BIV spectrin, a new spectrin localized at axon initial segments and nodes of Ranvier in the central and peripheral nervous system. J Cell Biol 151:985-1002.

Berglund AM, Ryugo DK (1987) Hair cell innervation by spiral ganglion neurons in the mouse. J Comp Neurol 255:560-570.
Boiko T, Rasband MN, Levinson SR, Caldwell JH, Mande G, Trimmer JS, Matthews G (2001) Compact myelin dictates the differential targeting of two sodium channel isoforms in the same axon. Neuron 30:91-104.

Boiko T, Wart AV, Caldwell JH, Levinston SR, Trimmer JS, Matthews G (2003) Functional specialization of the initial segment by isoformspecific sodium channel targeting. J Neurosci 23:2306-2313.

Brown MC (1987) Morphology of labeled efferent fibers in the guinea pig cochlea. J Comp Neurol 260:605-618.

Brown MC, Ledwith III JV (1990) Projections of thin (type-II) and thick (type-I) auditory-nerve fibers into the cochlear nucleus of the mouse. Hear Res 49:105-118.

Brownell WE, Bader CR, Bertrand D, de Ribaupierre Y (1985) Evoked mechanical responses of isolated cochlear outer hair cells. Science 227:194-196.

Caldwell JH, Schaller KL, Lasher RS, Peles E, Levinson SR (2000) Sodium channel Nav1.6 is localized at node of Ranvier, dendrites, and synapses. Proc Natl Acad Sci USA 10:5616-5620.

Cantrell AR, Catterall WA (2001) Neuromodulation of $\mathrm{Na}^{+}$channels: an unexpected form of cellular plasticity. Nat Rev Neurosci 2:397-407.

Dib-Hajj S, Black A, Cummins TR, Waxman SG (2002) NaN/Nav1.9: a sodium channel with unique properties. Trends Neurosci 25:253-259.

Durstewitz D, Seamans JK, Sejnowski TJ (2000) Dopamine-mediated stabilization of delay-period activity in a network model of prefrontal cortex. J Neurophysiol 83:1733-1750.

Garrido JJ, Giraud P, Carlier E, Fernandes F, Moussif A, Fache MP, Debanne D, Dargent B (2003) A targeting motif involved in sodium channel clustering at the axonal initial segment. Science 300:2091-2094.

Ginzberg RD, Morest DK (1983) A study of cochlear innervation in the young cat with the Golgi method. Hearing Res 10:227-246.

Ginzberg RD, Morest DK (1984) Fine structure of cochlear innervation in the cat. Hearing Res 14:109-127.

Goldstein SS, Rall W (1974) Changes of action potential shape and velocity for changing core conductor geometry. Biophys J 14:731-757.

Gong B, Rhodas KJ, Bekele-Arcuri Z, Trimmer JS (1999) Type I and Type II $\mathrm{Na}^{+}$channel alpha-subunit polypeptides exhibit distinct spatial and temporal patterning and association with auxiliary subunits in rat brain. J Comp Neurol 412:342-352.

Herzog RL, Cummins TR, Ghassemi F, Dib-Hajj SD, Waxman SG (2003) Distinct repriming and closed-state kinetics of $\mathrm{Na}_{\mathrm{v}} 1.6$ and $\mathrm{Na}_{\mathrm{v}} 1.7$ sodium channels in mouse spinal sensory neurons. J Physiol (Lond) 551:741-750.

Hines ML, Morse T, Migliore M, Carnevale NT, Shepherd GM (2004) Model DB: a database to support computational neuroscience. J Comput Neurosci 17:7-11.

Hodgkin AL, Huxley AF (1952) A quantitative description of membrane current and its application to conduction and excitation in nerve. J Physiol (Lond) 117:500-544.

Hurd LB, Hutson KA, Morest DK (1999) Cochlear nerve projections to the small cell shell of the cochlear nucleus: the neuroanatomy of extremely thin sensory axons. Synapse 33:83-117.

Isom LL, De Jongh KS, Catterall WA (1994) Auxiliary subunits of voltagegated ion channels. Neuron 12:1183-1194.

Kiang NY-S, Rho JM, Northrup CC, Liberman MC, Ryugo DK (1982) Hair cell innervation by spiral ganglion cells in adult cats. Science 217:175-177.

Komada M, Soriano P (2002) [Beta]IV-spectrin regulates sodium channel clustering through ankyrin-G at axon initial segments and nodes of Ranvier. J Cell Biol 156:337-348.

Lacas-Gervais S, Guo J, Strenzke N, Scarfone E, Kolpe M, Jahkel M, De Camilli P, Moser T, Rasband MN, Solimena M (2004) Beta-IV sigma-1 spectrin stabilizes the nodes of Ranvier and axon initial segments. J Cell Biol 166:983-990.

Lemaillet G, Walker B, Lambert S (2003) Identification of a conserved ankyrin-binding motif in the family of sodium channel alpha subunits. J Biol Chem 278:27333-27339.

Liberman MC, Brown MC (1986) Physiology and anatomy of single olivocochlear neurons in the cat. Hear Res 24:17-36.

Liberman MC, Dodd LW, Pierce S (1990) Afferent and efferent innervation of the cochlea: quantitative analysis with light and electron microscopy. J Comp Neurol 301:443-460.

Loewenstein WR, Ishiko N (1960) Effects of polarization of the receptor membrane and of the first Ranvier node in a sense organ. J Gen Physiol 43:981-998.

Luscher HR, Larkum ME (1998) Modeling action potential initiation and 
back-propagation in dendrites of cultured rat motoneurons. J Neurophysiol 80:715-729.

Mainen ZF, Sejnowski TJ (1996) Influence of dendritic structure on firing pattern in model neocortical neurons. Nature 382:363-366.

Maison SF, Adams JC, Liberman MC (2003) Olivocochlear innervation in the mouse: immunocytochemical maps, crossed versus uncrossed contributions, and transmitter colocalization. J Comp Neurol 455:406-416.

Migliore M, Messineo LO, Ferrante M (2004) Dendritic Ih selectively blocks temporal summation of unsynchronized sistal inputs in CA1 pyramidal neurons. J Comput Neurosci 16:5-13.

Mo Z-L, Adamson CL, Davis RL (2002) Dendrotoxin-sensitive $\mathrm{K}^{+}$currents contribute to accommodation in murine spiral ganglion neurons. J Physiol (Lond) 542:763-778.

Morest DK (1997) Structural basis for signal processing in the mammalian cochlear nuclei. Challenge of the synaptic nests. In: The mammalian cochlear nuclei: organization and function (Syka J, ed), pp 19-32. New York: Plenum.

Nicholls JG, Martin AR, Wallace BG, Fuchs PA (2001) From neuron to brain, Ed 4, pp 370-371. Sunderland, MA: Sinauer.

O'Leary ME (1998) Characterization of the isoform-specific differences in the gating of neuronal and muscle sodium channels. Can J Physiol Pharmacol 76:1041-1050.

Parkinson NJ, Olsson CL, Hallows JL, McKee-Johnson J, Keogh BP, NobenTrauth K, Kujawa SG, Tempel BL (2001) Mutant beta-spectrin 4 causes auditory and motor neuropathies in quivering mice. Nat Genet 29:61-65.

Parnas J, Hochstein S, Parnas H (1976) Theoretical analysis of parameters leading to frequency modulation along an inhomogeneous axon. J Neurophysiol 39:909-923.

Peles E, Nativ M, Lustig M, Grumet M, Schilling J, Martinez R, Plowman GD, Schlessinger J (1997) Identification of a novel contactin-associated transmembrane receptor with multiple domains implicated in proteinprotein interactions. EMBO J 16:978-988.

Perkins RE, Morest DK (1975) A study of cochlear innervation patterns in cats and rats with the Golgi method and Nomarski optics. J Comp Neurol 163:129-158.

Raman IM, Sprunger LK, Meisler MH, Bean BP (1997) Altered subthreshold sodium currents and disrupted firing patterns in Purkinje neurons of Scn8a mutant mice. Neuron 19:881-891.

Ramon F, Joyner RW, Moore JW (1975) Propagation of action potentials in inhomogeneous axon regions. Fed Proc 34:1357-1363.

Rasband MN, Trimmer JS (2001) Subunit composition and novel localization of $\mathrm{K}^{+}$channels in spinal cord. J Comp Neurol 429:166-176.

Rasband MN, Peles E, Trimmer JS, Levinson SR, Lux SE, Shrager P (1999a) Dependence of nodal sodium channel clustering on paranodal axoglial contact in the developing CNS. J Neurosci 19:7516-7528.

Rasband MN, Trimmer JS, Peles E, Levinson SR, Shrager P (1999b) $\mathrm{K}^{+}$ channel distribution and clustering in developing and hypomyelinated axon of the optic nerve. J Neurocytol 28:319-331.

Rasband MN, Kagawa T, Park EW, Ikenaka K, Trimmer JS (2003) Dysregulation of axonal sodium channel isoforms after adult-onset chronic demyelination. J Neurosci Res 73:465-470.

Rhodes PA, Llinas RR (2001) Apical tuft input efficacy in layer 5 pyramidal cells from rat visual cortex. J Physiol (Lond) 536:167-187.

Rios JC, Rubin M, St. Martin M, Downey RT, Einheber S, Rosenbluth J, Levinson SR, Bhat M, Salzer JL (2003) Paranodal interactions regulate expression of sodium channel subtypes and provide a diffusion barrier for the node of Ranvier. J Neurosci 23:7001-7011.
Robertson D (1976) Possible relation between structure and spike shapes of neurons in guinea pig cochlear ganglion. Brain Res 109:487-496.

Robertson D, Sellick PM, Patuzzi R (1999) The continuing search for outer hair cell afferents in the guinea pig spiral ganglion. Hearing Res 136:151-158.

Romand MR, Romand R (1987) The ultrastructure of cochlear ganglion cells in the mouse. Acta Otolaryngol 104:29-39.

Rosenbluth J (1962) The fine structure of acoustic ganglia in the rat. J Cell Biol 12:329-359.

Russell I, Palmer A (1986) Filtering due to the inner hair-cell membrane properties and its relation to the phase-locking limit in cochlear nerve fibers. In: Auditory frequency selectivity (Moore BCJ, Patterson RD, eds), pp 199-206. New York: Plenum.

Sangameswaran L, Fish LM, Koch BD, Rabert DK, Delgado SG, Ilnicka M, Jakeman LB, Novakovic S, Wong K, Sze P, Tzoumaka E, Stewart GR, Herman RC, Chan M, Eglen RM, Hunter JC (1997) A novel tetrodotoxin-sensitive, voltage-gated sodium channel expressed in rat and human dorsal root ganglia. J Biol Chem 262:14805-14809.

Santos-Sacchi J (1993) Voltage-dependent ionic conductances of type I spiral ganglion cells from the guinea pig inner ear. J Neurosci 13:3599-3611.

Schaller KL, Caldwell JH (2003) Expression and distribution of voltagegated sodium channels in the cerebellum. Cerebellum 2:2-9.

Siegel JH (1992) Spontaneous synaptic potentials from afferent terminals in the guinea pig cochlea. Hear Res 59:85-92.

Siegel JH, Dallos P (1986) Spike activity recorded from the organ of Corti. Hear Res 22:245-248.

Spoendlin H (1973) The innervation of the cochlear receptor. In: Basic mechanisms in hearing (Møller AR, ed), pp 185-234. New York: Academic.

Szabo ZS, Harasztosi CS, Sziklai I, Szucs G, Rusznak Z (2002) Ionic currents determining the membrane characteristics of type I spiral ganglion neurons of the guinea pig. Eur J Neurosci 16:1887-1895.

Toledo-Aral JJ, Moss BI, He ZJ, Koszowski AG, Whisenand T, Levinson SR, Wolf JJ, Silos-Santiago I, Halegoua S, Mandel G (1997) Identification of PN1, a predominant voltage-dependent sodium channel expressed principally in peripheral neurons. Proc Natl Acad Sci USA 94:1527-1532.

Traub RD, Buhl EH, Gloveli T, Whittington MA (2003) Fast rhythmic bursting can be induced in layer $2 / 3$ cortical neurons by enhancing persistent $\mathrm{Na}^{+}$conductance or by blocking BK channels. J Neurophysiol 89:909-921.

Vetter P, Roth A, Hausser M (2001) Propagation of action potentials in dendrites depends on dendritic morphology. J Neurophysiol 85:926-937.

Wang LY, Gan L, Forsythe ID, Kaczmarek LK (1998) Contribution of the Kv3.1 potassium channel to high-frequency firing in mouse auditory neurones. J Physiol (Lond) 509:183-194.

Westenbroek RE, Merrick DK, Catterall WA (1989) Differential subcellular localization of the RI and RII $\mathrm{Na}^{+}$channel subtypes in central neurons. Neuron 3:695-704.

Whitlon DS, Szakaly R, Greiner MA (2001) Cryoembedding and sectioning of cochleas for immunocytochemistry and in situ hybridization. Brain Res Brain Res Protoc 6:159-166.

Yang Y, Lacas-Gervais S, Morest DK, Solimena M, Rasband MN (2004) $\beta I V$ spectrins are essential for membrane stability and the molecular organization of nodes of Ranvier. J Neurosci 24:7230-7240.

Young ED, Oertel D (2004) Cochlear nucleus. In: The synaptic organization of the brain (Shepherd GM, ed), pp 125-163. New York: Oxford UP. 